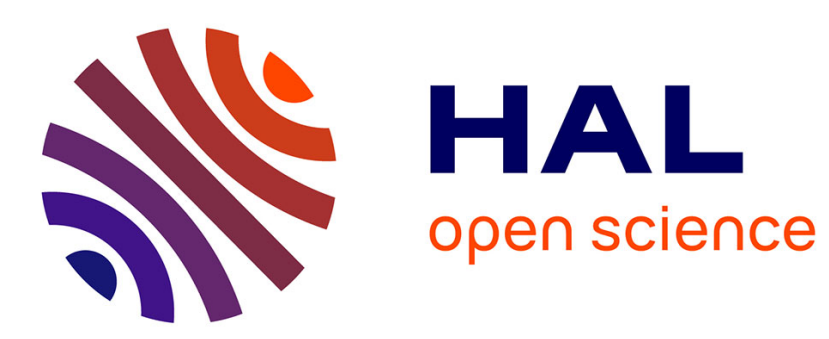

\title{
Expectations and Bubbles in Asset Pricing Experiments
}

Cars Hommes, Joep Sonnemans, Jan Tuinstra, Henk van de Velden

\section{To cite this version:}

Cars Hommes, Joep Sonnemans, Jan Tuinstra, Henk van de Velden. Expectations and Bubbles in Asset Pricing Experiments. Journal of Economic Behavior and Organization, 2008, 67 (1), pp.116. 10.1016/j.jebo.2007.06.006 . hal-00598268

\section{HAL Id: hal-00598268 https://hal.science/hal-00598268}

Submitted on 6 Jun 2011

HAL is a multi-disciplinary open access archive for the deposit and dissemination of scientific research documents, whether they are published or not. The documents may come from teaching and research institutions in France or abroad, or from public or private research centers.
L'archive ouverte pluridisciplinaire HAL, est destinée au dépôt et à la diffusion de documents scientifiques de niveau recherche, publiés ou non, émanant des établissements d'enseignement et de recherche français ou étrangers, des laboratoires publics ou privés. 


\section{Accepted Manuscript}

Title: Expectations and Bubbles in Asset Pricing Experiments

Authors: Cars Hommes, Joep Sonnemans, Jan Tuinstra, Henk van de Velden

PII:

S0167-2681(07)00162-X

DOI: doi:10.1016/j.jebo.2007.06.006

Reference: JEBO 2134

To appear in: Journal of Economic Behavior \& Organization

Received date: 27-5-2005

Accepted date: $\quad$ 21-6-2007

Please cite this article as: Hommes, C., Sonnemans, J., Tuinstra, J., van de Velden, H., Expectations and Bubbles in Asset Pricing Experiments, Journal of Economic Behavior and Organization (2007), doi:10.1016/j.jebo.2007.06.006

This is a PDF file of an unedited manuscript that has been accepted for publication. As a service to our customers we are providing this early version of the manuscript. The manuscript will undergo copyediting, typesetting, and review of the resulting proof before it is published in its final form. Please note that during the production process errors may be discovered which could affect the content, and all legal disclaimers that apply to the journal pertain. 


\title{
Expectations and Bubbles in Asset Pricing Experiments
}

\author{
Cars Hommes* Joep Sonnemans $^{\dagger} \quad$ Jan Tuinstra ${ }^{\ddagger}$ \\ Henk van de Velden ${ }^{\S}$ \\ Universiteit van Amsterdam
}

February 2007

JEL classification code: C91, C92, D84, G12, G14

Acknowledgements: We benefitted from comments by two anonymous referees and seminar participants at the Universities of Amsterdam, Dortmund, Groningen and Maastricht. Financial support under a NWO-Pionier grant is gratefully acknowledged.

*Department of Quantitative Economics and CeNDEF, Universiteit van Amsterdam, Roetersstraat 11, 1018 WB, Amsterdam, The Netherlands. E-mail: C.H.Hommes@uva.nl. Tel.: +31-20-525-4246; fax: +31-20-525-4248.

${ }^{\dagger}$ Department of Economics and CREED, Universiteit van Amsterdam, Roetersstraat 11, 1018 WB, Amsterdam, The Netherlands. E-mail: J.H.Sonnemans@uva.nl.

${ }^{\ddagger}$ Department of Quantitative Economics and CeNDEF, Universiteit van Amsterdam, Roetersstraat 11, 1018 WB, Amsterdam, The Netherlands. E-mail: J.Tuinstra@uva.nl.

$\S$ Bank van de Nederlandse Antillen, Willemstad, Curaçao, Netherlands Antilles. E-mail: H.vandeVelden@centralbank.an. The research presented here was carried out when this author was affiliated with the Department of Quantitative Economics and CeNDEF, Universiteit van Amsterdam as a $\mathrm{PhD}$ student. 


\title{
Expectations and Bubbles in Asset Pricing Exper- iments
}

\begin{abstract}
We present results on expectation formation in a controlled experimental environment. In each period subjects are asked to predict the next price of a risky asset. The realized market price is derived from an unknown market equilibrium equation with feedback from individual forecasts. In most experiments prices deviate from the benchmark fundamental and bubbles emerge endogenously. These bubbles are inconsistent with rational expectations and seem to be driven by trend chasing behavior or "positive feedback expectations" of the participants. We also analyze individual predictions of participants and find that participants within a group tend to coordinate on a common prediction strategy.
\end{abstract}

Keywords: experimental economics, expectations, asset pricing, speculative bubbles

JEL classification code: C91, C92, D84, G12, G14 


\section{Introduction}

The exuberant rise and fall in stock prices in recent years has drawn renewed attention to the possible existence of so-called speculative price bubbles. Such bubbles, where a stock is traded at prices significantly higher than (and seemingly unrelated to) the fundamental value of the stock, are closely related to traders' (optimistic) expectations about the future price of the stock. Traders buy an asset that is already 'overpriced' because they expect the price of this asset to increase even more and they want to benefit from the perceived capital gains of a further price increase.

There have been many empirical studies on the question of whether part of the fluctuations in stock prices can be attributed to speculative price bubbles (see for example Flood and Garber 1980, West 1987, Froot and Obstfeld, 1991). Garber (1990), for example, argues that even the widely acknowledged "classical" bubbles known as the Dutch Tulipmania (1634-1637), the Mississippi Bubble (1719-1720) and the South Sea Bubble (1720) can be explained, to a large extent, by changes in market fundamentals. There are also some theoretical papers on the possibility of rational bubbles (i.e., speculative price bubbles consistent with rational expectations). Tirole (1982) claims that in a model with a finite number of infinitely lived traders, common knowledge of rationality inhibits the possibility of trade against prices different from the market fundamental. Trade against nonfundamental prices can occur if traders do not have a common prior about the distribution of private signals about the fundamental value. Tirole (1985) shows that rational bubbles are possible in an overlapping generations model with finitely lived traders, provided that the growth rate of the economy is larger than the return on the stock. Diba and Grossman (1988) use the nonnegativity of stock prices to rule out the existence of rational bubbles. Finally, Santos and Woodford (1997) analyse the possibility of bubbles in a general intertemporal competitive equilibrium framework. They conclude that rational bubbles can occur only under rather special circumstances.

The occurrence of price bubbles in experimental asset markets is less controversial. The possibility of experimental bubbles was first recognized in an intriguing paper by Smith et al. (1988). They investigate an experimental asset market where an asset is traded that pays (uncertain) dividends for 15 consecutive periods. Participants differ only in their endowments of the number of stocks and the amount of money, but there is no asymmetric information. Bubbles, where the asset is traded at prices above the fundamental value, emerge in most of the experiments. This remarkable finding has been corroborated in many other asset market experiments, with varying designs (e.g., King et al. 1993, Porter and Smith 1995, Noussair et al. 2001, Smith et al. 2000).

Many of these experimenters conjecture that expectations play an important role in generating bubbles. Referring to the theoretical result by Tirole (1982), Smith et al. conjecture that it is a lack of common expectations (i.e., a lack of a common prior) that drives the emergence of bubbles. That is, although every participant has the same information, a participant engages in trade at a price higher than the intrinsic value of the stock because he or she believes it possibble to sell it to somebody later on at an even higher price. However, in a recent experimental paper Lei et al. (2001) 
show that, even if speculation is prohibited (that is, a subject can only buy or only sell the asset, but subjects are not able to do both in order to reap the capital gains), bubbles occur. They claim that this points to irrationality of participants instead of a lack of common expectations.

Although their main interest lies with the trading decisions of participants, Smith et al. also try to obtain explicit information on the expectations of the participants of the experiment. In some of their experiments each participant is asked to give a forecast for the mean trading price. The participant with the lowest mean forecast error over the course of the experiment earns an additional $\$ 1.00$. Williams (1987) uses the same method to study expectation formation in an experimental double auction market. However, in both kinds of experiments observations on expectation formation follow as a by-product of the experiment and might therefore not be very accurate. $^{1}$

In the present paper we present an experiment which focuses explicitly on expectation formation of participants. We consider a standard asset pricing framework, where the only task for the participants is to predict the asset price for the next period. They do not have knowledge of the underlying market equilibrium equation, but they know all past realized prices and, of course, their own predictions. Furthermore, they have perfect knowledge about the dividend process and could use this to compute the rational expectations fundamental price. In fact, the dividend process is IID so that the corresponding rational expectations fundamental price is constant. Participants' earnings are inversely related to the average prediction error they make. Given the price forecast of a participant, a computer program computes the associated optimal trading decision and subsequently the market equilibrium price. Clearly, the realized price is a function of the individual forecasts. This expectations feedback is an important feature of economic dynamic systems in general and financial markets in particular. Our experiment is designed such that we obtain explicit information about the expectations of participants in such a controlled expectations feedback environment.

Our main contribution is that, even in this simple stationary setup, price bubbles emerge. This is due to so-called positive feedback expectations; that is, participants seem to extrapolate trends in realized asset prices into the future. If the asset price increases (decreases), participants expect a further increase (decrease). This expected price increase (decrease) is self-fulfilling and leads to a further price increase (decrease). The current paper is the first to establish this type of purely expectationsdriven experimental price bubbles. We also analyze individual predictions, and a second important result is that the forecasts are very similar for participants in the same group. Therefore coordination on a common prediction strategy occurs, which contrasts with the conjecture of lack of common expectations by Smith et al. (1988).

There is substantial evidence that many people, much like the participants in our experiment, try to extrapolate trends when forecasting the price of a stock (see also Hirshleifer 2001, Barberis and Thaler 2003, section 5). This implies that these

\footnotetext{
${ }^{1}$ This is also argued in Hey (1994) who points out that (p.230) "In these studies, the question of expectations formation has tended to be of rather peripheral concern, with the data on expectations elicited in a somewhat unsatisfactory and only partial motivated manner."
} 
people will buy (sell) the stock if its price has increased (decreased) in anticipation of a further price increase (decrease). De Long et al. (1990) call such traders positive feedback traders. Many trading strategies used by professional investors search for trends in the data and give buy or sell signals on the basis of an extrapolation of such trends. There is also experimental and empirical evidence on extrapolative expectations and positive feedback trading. In Andreassen and Kraus (1990) several experimental studies are described where participants are confronted with a historical stock price series and are asked to trade stocks at these prices in order to maximize their wealth. After they have made a trading decision the next price, which is independent of their trading decision and forecasts, is revealed. Apparently participants tend to buy when prices are low and sell when prices are high, which is consistent with conventional economic wisdom. However, when the saliency of price changes is high; that is, when similar price changes occur often, the variance of these changes is low or the mean absolute value of these changes is large, participants tend to use price changes instead of price levels, for making a trading decision. In that case they are more likely to buy (sell) stock when the price has been rising (falling). De Bondt (1993) presents further evidence from experiments and surveys that people tend to extrapolate trends when predicting stock prices. Finally, Frankel and Froot (1988) investigate survey data on exchange rates and find that, in the short run, traders expect the exchange rate to depreciate further after a depreciation.

Although it has been recognized for quite some time that a theory of how people form expectations and learn in an expectations feedback environment is important for understanding many economic phenomena (see e.g. the survey by Evans and Honkapohja 2001), our work is among the first to experimentally test expectations in such an environment. The experimental approach indeed seems very suitable for studying expectations, since it provides explicit observations on expectations in a controlled environment, which is an advantage over using survey data about expectations (as is done, for example, by Frankel and Froot 1987, 1988, Shiller 1990). The only earlier paper employing a method similar to ours is Marimon et al. (1993). They solicit predictions from participants in an overlapping generations framework, and the computer program then computes the associated optimal demand. There have been a number of other experiments designed to study expectation formation in a time series context (e.g. Schmalensee 1976, Dwyer et al. 1993, Hey 1994), but these experiments disregard the expectations feedback, which is a key feature of dynamic economic models and which we want to account for explicitly. In van de Velden (2001) the experimental approach is used for investigating expectation formation in a simple cobweb type commodity market with a production lag structure. There it was shown that, for an unstable cobweb model, the heterogeneity of expectations leads to excess volatility of realized prices. In another closely related paper, Hommes et al. (2005) run experiments in an asset pricing environment similar to the one studied here, but with a structure that inhibits the possibility of price bubbles. In particular, in the experiment presented in that paper an upper bound on prices and predictions is used that is much lower than the one in the experiment presented here. Moreover, the experiment in Hommes et al. includes a fundamentalist 'robot' trader, who always predicts the fundamental price and has a stabilizing impact on asset prices. 
The paper is organized as follows. In Section 2 we discuss the asset pricing model we use in the experiment. Section 3 describes the design of the experiment. ${ }^{2}$ Section 4 presents an analysis of the aggregate behavior of the asset prices and Section 5 discusses the individual prediction strategies. Concluding remarks are given in Section 6.

\section{Asset Prices and Expectations}

\subsection{The asset pricing model}

Consider an asset market with $H$ traders, indexed by $h$. A trader can invest his money in a risk free asset (e.g., a savings deposit) with a risk free gross rate of return $R=1+r$, where $r$ is the real interest rate, or he can invest his money in shares of an infinitely lived risky asset. The price of this risky asset in period $t$ is $p_{t}$. Furthermore, for each share dividends $y_{t}$ are paid out in period $t$. We assume these dividends to be independently and identically distributed with mean $\bar{y}$ and variance $\sigma_{y}^{2}$. Denote by $z_{h t}$ the number of shares of the risky asset purchased by trader $h$ in period $t$. Note that $z_{h t}$ can be positive as well as negative. If it is negative it means that trader $h$ sells a number of shares of the risky asset in period $t$. The trader's realized wealth in period $t+1$ then is

$$
W_{h, t+1}=R W_{h, t}+\left(p_{t+1}+y_{t+1}-R p_{t}\right) z_{h t} .
$$

Traders' subjective beliefs about the evolution of wealth are characterized by their subjective conditional mean $E_{h t}$ and their subjective conditional variance $V_{h t}$. Traders are mean-variance optimizers; that is, their demand for shares corresponds to the solution to

$$
\begin{aligned}
\max _{z_{h t}} U_{h}\left(W_{t+1}\right) & =\max _{z_{h t}}\left\{E_{h t}\left(W_{t+1}\right)-\frac{1}{2} a V_{h t}\left(W_{t+1}\right)\right\} \\
& =\max _{z_{h t}}\left\{z_{h t} E_{h t}\left(p_{t+1}+y_{t+1}-R p_{t}\right)-\frac{1}{2} a z_{h t}^{2} V_{h t}\left(p_{t+1}+y_{t+1}-R p_{t}\right)\right\},
\end{aligned}
$$

where $a$ measures the degree of risk aversion (assumed to be the same for all traders). We assume $V_{h t}\left(p_{t+1}+y_{t+1}-R p_{t}\right)=\sigma^{2}$, for all $h$; that is, traders believe that the conditional variance of excess returns is constant (and this constant is the same for all traders). There is no harm in this assumption since the present paper deals only with point predictions of traders and not with traders' beliefs about the distribution of returns. The solution is given by

$$
z_{h t}=\frac{E_{h t}\left(p_{t+1}+y_{t+1}-R p_{t}\right)}{a \sigma^{2}} .
$$

Let $z^{s}$ denote the outside supply of shares. The market equilibrium condition now becomes

$$
\sum_{h=1}^{H} z_{h t}=\frac{1}{a \sigma^{2}} \sum_{h=1}^{H} E_{h t}\left(p_{t+1}+y_{t+1}-R p_{t}\right)=z^{s} .
$$

\footnotetext{
${ }^{2}$ An appendix containing some auxiliary information about the experimental setup is available on the JEBO website.
} 
Notice that today's asset price is determined by beliefs about tomorrow's asset price and dividend. Hence, when traders have to make a prediction for the price in period $t+1$ they do not know the price in period $t$ yet, and they can only use information up till time $t-1$. Without loss of generality we assume that there is no outside supply of shares, $z^{s}=0$. Equation (1) can then be interpreted as excess demand. The market equilibrium equation (2) can now be rewritten as

$$
R p_{t}=\frac{1}{H} \sum_{h=1}^{H} E_{h t}\left(p_{t+1}+y_{t+1}\right) .
$$

An important feature of the asset pricing model is its self-confirming nature: if all traders have a high (low) prediction the realized price will also be high (low). This feature is characteristic for a speculative asset market: if traders expect a high price, the demand for the risky asset will be high, and as a consequence the realized market price will be high, assuming that the supply is fixed.

The basic equation of the asset pricing model is equation (3). The development of the asset price depends upon the (subjective) expectations of the traders. We will consider the dynamics of the asset pricing model under rational expectations in Subsection 2.2. In Subsection 2.3 we will discuss the dynamics of the asset pricing model under boundedly rational prediction strategies.

\subsection{The fundamental solution and rational bubbles}

Under rational expectations the subjective expectation $E_{h t}$ of trader $h$ is equal to the objective mathematical conditional expectation $E_{t}$, for all $h$. Equation (3) then reduces to

$$
R p_{t}=E_{t}\left(p_{t+1}+y_{t+1}\right) .
$$

After $K$ steps of repeated substitution we find

$$
p_{t}=\frac{E_{t}\left(p_{t+K}\right)}{R^{K}}+\sum_{k=1}^{K} \frac{E_{t}\left(y_{t+k}\right)}{R^{k}},
$$

where we have used $E_{t} E_{t+k}()=.E_{t}($.$) for k>0$. There are two types of solutions. Sometimes the solution paths are required to satisfy the no-bubbles condition $\lim _{K \rightarrow \infty} \frac{E_{t}\left(p_{t+K}\right)}{R^{K}}=0$. Given this condition we have

$$
p_{t}=\sum_{k=1}^{\infty} \frac{E_{t}\left(y_{t+k}\right)}{R^{k}}
$$

which equals the present discounted value of the expected future dividends. This solution will be denoted the fundamental price $p^{f}$. For the IID dividend process that we have specified, this fundamental price is

$$
p^{f}=\frac{\bar{y}}{R-1}=\frac{\bar{y}}{r}
$$




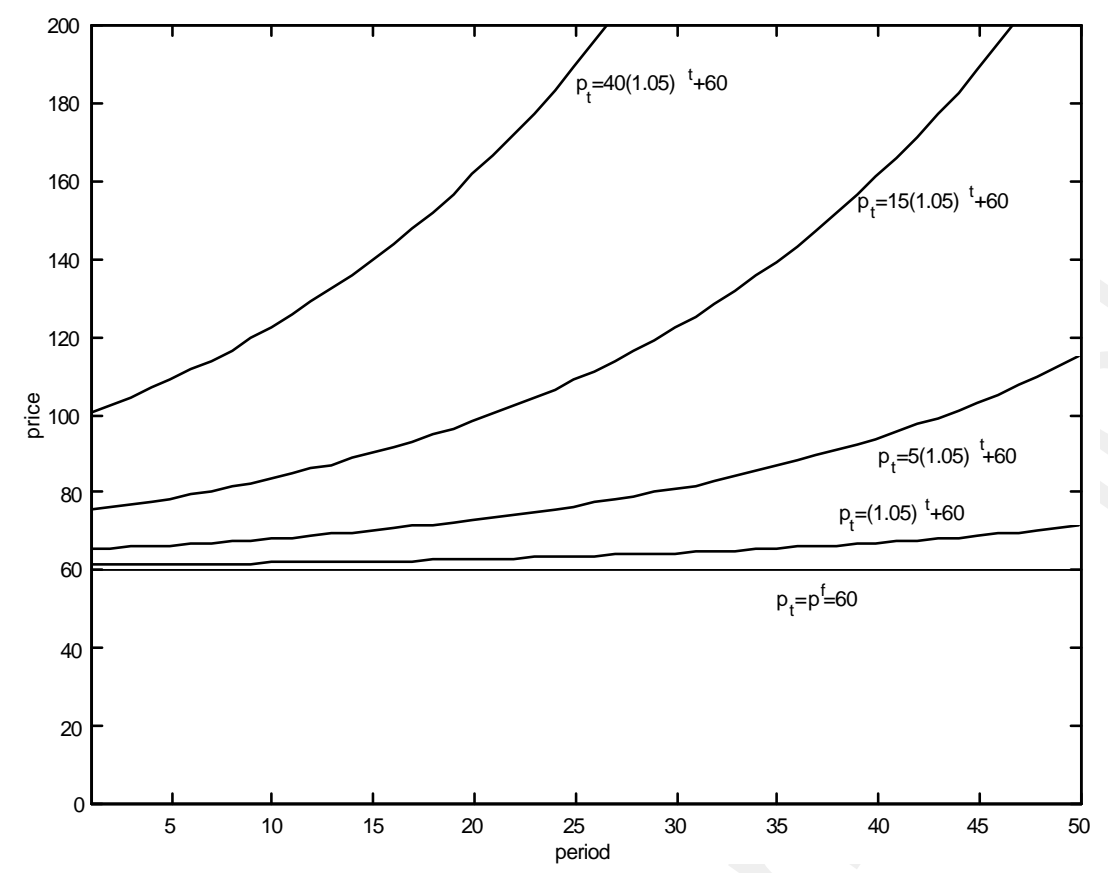

Figure 1: Fundamental value and rational bubbles in the asset pricing model

According to the efficient market hypothesis the price of the asset should be equal to $p_{t}=p^{f}$, for all $t$. However, there is, a priori, no convincing reason why the nobubbles condition should hold. In fact, it can easily be checked that under rational expectations any solution of the form

$$
p_{t}^{b}=R^{t} c+p^{f}=R^{t} c+\frac{\bar{y}}{r}, \quad c \geq 0
$$

is a rational expectations solution satisfying (3). These solutions are called rational bubbles. They grow with a rate $R$, and a solution exists for each $c \geq 0$. Hence, under rational expectations there is a continuum of (exploding) solution orbits. Note that both types of rational expectations solutions correspond to self-fulfilling perfect foresight expectations: when all traders predict the fundamental price, the realized market will be equal to the fundamental price, and when all traders believe that the price deviation from the fundamental grows by the gross rate of return each period, the price of the asset will indeed grow with the gross rate of return.

Figure 1 shows the fundamental solution and four rational bubble solutions. The values of the parameters $\bar{y}$ and $r$ correspond to the parameter values in our experimental design. An important question we try to answer in this paper is whether the participants in the experimental asset market will coordinate on the fundamental solution or on one of the rational bubble solutions. 


\subsection{Boundedly rational prediction strategies}

The rational expectations hypothesis is quite demanding. It requires that traders know the underlying asset pricing model and use this to compute the conditional expectation for the future price and that they do not make structural forecast errors. In particular, in a heterogeneous world rational expectations requires knowledge about the beliefs of all other traders. A rational expectations solution will only prevail when traders are able to coordinate on one of the possible rational expectations equilibria. In this section we discuss the asset pricing model when agents use simple forecasting rules. They do not have (exact) knowledge of the underlying model, but have their own beliefs about the development of asset prices and use this belief and the available time series observations to predict the price. The beliefs of the traders are sometimes called the perceived laws of motion. Given these perceived laws of motion the underlying model (3) is then referred to as the implied actual law of motion. An important objective of this paper is to get some insight into the nature of the perceived laws of motion people actually use. We assume that when traders have to predict a price for time $t+1$, they know the interest rate $r$ (which is constant over time), the realized prices up to time $t-1$ and their own price predictions up to time $t$. We assume that the IID dividend process $y_{t}=\bar{y}+\delta_{t}$ is common knowledge and $E_{h t} y_{t}=\bar{y}$ for all $h$ and all $t$. The market equilibrium price in (3) then simplifies to

$$
p_{t}=\frac{1}{R H} \sum_{h=1}^{H} E_{h t}\left(p_{t+1}\right)+\frac{\bar{y}}{R}
$$

A general form of a trader's forecasting rule or prediction strategy is

$$
E_{h t}\left(p_{t+1}\right)=p_{h, t+1}^{e}=f_{h}\left(p_{t-1}, p_{t-2}, \ldots, p_{1}, p_{h t}^{e}, p_{h, t-1}^{e}, \ldots, p_{h 1}^{e}, \bar{y}, r\right),
$$

where $f_{h}$ can be any (possibly time-varying) function. There are no restrictions on the specification $f_{h}$, and the possibilities are therefore unbounded. ${ }^{3}$ Given traders' forecasting rules (5), the implied actual law of motion becomes

$$
p_{t}=\frac{1}{R H} \sum_{h=1}^{H} f_{h}\left(p_{t-1}, p_{t-2}, \ldots, p_{1}, p_{h t}^{e}, p_{h, t-1}^{e}, \ldots, p_{h 1}^{e}, \bar{y}, r\right)+\frac{\bar{y}}{R} .
$$

The actual dynamics of prices is to a great extent characterized by the prediction strategies used by the traders. Depending on the prediction strategies used by the agents, almost any type of price behavior can occur. Brock and Hommes (1998), for example, study an evolutionary competition between different prediction strategies in this framework and find that this may lead to complicated dynamics, possibly with asset prices and returns moving on a strange attractor.

An important feature of our asset pricing model is that it is stable in the sense that if traders (on average) do not expect prices to diverge too fast, the asset price

\footnotetext{
${ }^{3}$ Notice that traders have all necessary information (the risk free rate of return $r$ and the mean dividend $\bar{y}$ ) to calculate the fundamental price $p^{f}=\frac{\bar{y}}{r}$ and use this as their forecast.
} 
will converge to a steady state. Consider, for example, the case where traders have naive or static expectations, where

$$
p_{h, t+1}^{e}=p_{t-1}
$$

that is, their prediction for the next price corresponds to the last observed asset price. Under the assumption that all traders have naive expectations the implied law of motion becomes a linear difference equation

$$
p_{t}=\frac{1}{1+r}\left(p_{t-1}+r p^{f}\right)
$$

which has steady state $p^{f}=\frac{\bar{y}}{r}$ and slope $\frac{1}{1+r}$. Since the slope lies between 0 and 1 , prices converge monotonically to the steady state. The asset pricing model is stable under naive expectations, and there is (slow and monotonic) convergence to the steady state because the slope is close to 1 . The stability property is a more general characteristic of the model as can be seen by rewriting (3) as

$$
p_{t}-p^{f}=\frac{1}{1+r}\left(\bar{p}_{t+1}^{e}-p^{f}\right),
$$

where $\bar{p}_{t+1}^{e}=\frac{1}{H} \sum_{h=1}^{H} p_{h, t+1}^{e}$ is the average prediction for period $t+1$. It follows that the realized price will always lie between the average price prediction $\bar{p}_{t+1}^{e}$ and the fundamental price $p^{f}=\frac{\bar{u}}{r}$. If traders on average do not extrapolate too strongly, the fundamental steady state is stable. The convergence may be slow, however. The fundamental steady state is also locally stable under more sophisticated forms of learning, such as least squares learning (see Evans and Honkapohja, pp.220-222) or eductive learning (see Guesnerie 2002).

It should be clear that bubbles can only occur in this framework if traders expect them to occur. For example, if traders believe that prices grow with rate $\beta>\sqrt{R}$ each period, their predictions are given by

$$
p_{h, t+1}^{e}=\beta^{2} p_{t-1}
$$

and prices in fact grow with rate $\frac{\beta^{2}}{R}>1$. We will refer to these exploding solutions as speculative bubbles. As noted before, the asset pricing model has a self-confirming nature: if traders expect prices to explode, it is likely that prices will indeed explode. In fact, if $\beta$ is close to $R$ these bubble expectations are approximately self-fulfilling.

\section{Experimental design}

We consider an experimental asset pricing model with 6 participants per market, where each market lasts for 50 periods. In total 36 subjects (6 groups) participated in this experiment. Subjects (mostly undergraduates in economics, chemistry and psychology) were recruited by means of announcements on information boards in university buildings. The computerized experiment was conducted in the CREED 
laboratory. It lasted for approximately 1.5 hours, and average earnings were 21.63 Dutch guilders ( $\approx 9.81$ EURO).

In financial markets traders are involved in two related activities: prediction and trade. They make a prediction concerning the future price of the risky asset, and given this prediction, they make a trading decision. The experiment is aimed at investigating the way subjects form predictions. Given the predictions made by subjects the computer derives individual demand from mean-variance maximization as given by the optimal demand function (1). Each subject therefore acts as an advisor or a professional forecaster and is paired with one computerized trader, which may be thought of as a large pension fund. The subject has to make the most accurate prediction for this trader, and then the trader (i.e., the computer) decides how much to trade. The earnings of the subjects in the experiment are determined by their prediction accuracy.

The experiment is presented to the participants as follows. The participants are told that they are an advisor to a pension fund and that this pension fund can invest its money in a risky asset (the stock market) or in a risk free asset (a bank account). The task of the advisor (i.e., the participant) is to predict the price of the risky asset. Participants know that the price of the asset is determined by market equilibrium between demand and supply of the asset. Although they do not know the exact underlying market equilibrium equation, they are informed that the higher their forecast is, the larger will be the fraction of money invested in the risky asset and the larger will be the demand for stocks. They also have information about fundamentals: they know the mean dividend $\bar{y}$ and the interest rate $r$. Participants do not know the investment strategy of the pension fund they are advising and the investment strategies of the other pension funds. They also do not know how many pension funds are in this market exactly, and they do not know the identity of the other members of the group.. They are not explicitly informed about the fact that the price of the asset depends on their prediction and the prediction of the other participants.

The information for the participants is given in computerized instructions. Comprehension of the instructions is checked by two control questions. At the beginning of the experiment the participants are given two sheets of paper with a summary of all necessary information, general information, information about the stock market, information about the investment strategies of the pension funds, forecasting task of the financial advisor and information about the earnings. The information on the handout summarizes the computerized instructions. The handout also contains information about the financial parameters (mean dividend and risk free rate of return) with which an accurate prediction of the fundamental price can be made. Finally they are given a table from which they can read, for a given forecast error, their earnings (see Appendix $B$ ). Appendix $A$ contains an English translation of the information given to the participants.

In every period $t$ in the experiment the task of the participants is to predict the price of the risky asset in period $t+1$, given the available information. This information consists of past prices of the risky asset $p_{t-1}, p_{t-2}, \ldots, p_{1}$ and past individual predictions $p_{h t}^{e}, p_{h, t-1}^{e}, \ldots, p_{h 1}^{e}$. Recall that participants also know the interest rate 

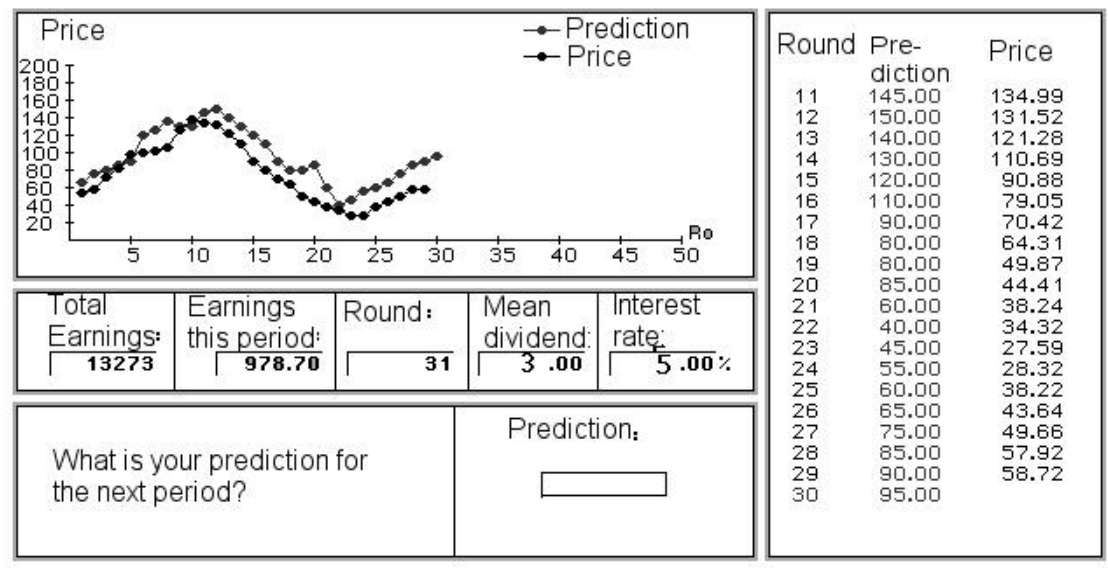

E

Figure 2: English translation of the computer screen as seen by the participants during the experiment. Predictions and prices have different colors. The $Y$-axis is $0-100$ to start with, but is rescaled when prices $\backslash$ predictions are above $100(200,300$, etc.).

$r=0.05$ and the mean $\bar{y}=3$ of the IID dividend process. In periods 1 and 2 no information about past prices is available, but the subjects are told that their price forecast has to be between 0 and 100 in these first two periods (notice that the fundamental price in our experiment equals $p^{f}=\frac{\bar{y}}{r}=60$ ). For practical reasons, we had to impose an upper bound on prices and predictions. We chose this upper bound to be equal to 1000. The participants are not informed about this in advance. If, in a certain period, a participant predicts a price higher than 1000, the computer screen will notify him or her that predictions above 1000 are not accepted and that the participant has to submit a new and lower prediction. ${ }^{4}$

At the end of period $t$, when all predictions for period $t+1$ have been submitted, the participants are informed about the realized market price in period $t$ and earnings for that period are revealed. Figure 2 shows an English translation of the computer screen the participants are facing during the experiment. On the screen the subjects are informed about their earnings in the previous period, total earnings, a table of the last twenty prices and the corresponding predictions and a time series of the prices and the predictions.

Recall that the market equilibrium price is given by

\footnotetext{
${ }^{4}$ The choice not to inform participants about the upper bound of 1000 was motivated by the fact that such an upper bound also does not exist in real financial markets. Moreover, we did not expect the upper bound would be reached, since it is 10 times the upper bound of 100 of the first period (which is also used in Hommes et al.) and the most explosive rational bubble (eq. (4) with $c=40$ ) reaches the upper bound not earlier than at $t=65$. However, since in most experimental groups the upper bound was reached, some participants received additional information during the experiment. A potential problem, pointed out to us by a referee, is that participants might talk about this upper bound in between sessions. The similarity between results from different sessions suggests that this did not happen. In the remainder of the paper we focus primarily on what happens before the upper bound is reached for the first time.
} 


$$
p_{t}=\frac{1}{1+r}\left[\frac{1}{6} \sum_{h=1}^{6} p_{h, t+1}^{e}+\bar{y}\right],
$$

where $H=6$ is the number of participants. The earnings of the participants consist of a "show-up" fee of 10 Dutch guilders (1 Dutch guilder is approximately 0.45 EURO) and of the earnings from the experiment that depend upon their forecasting errors. The number of points earned in period $t$ by participant $h$ is given by the quadratic scoring rule

$$
e_{h t}=\max \left\{1300-\frac{1300}{49}\left(p_{t}-p_{h t}^{e}\right)^{2}, 0\right\},
$$

where 1300 points is equivalent to 1 Dutch guilder. Given their role as advisors it seems reasonable to reward participants according to their prediction accuracy. ${ }^{5}$ Notice that earnings are zero in period $t$ when $\left|p_{t}-p_{h t}^{e}\right|>7$ in order to shield participants from losing money in the experiment.

\section{Aggregate behavior of asset prices}

In this section we discuss the aggregate behavior of the asset prices. ${ }^{6}$ Figure 3 gives the realized prices for the six different sessions. The most striking feature is that in 5 of the 6 groups the realized price approaches 1000 and subsequently drops, and hence a bubble seems to occur in these groups. In 4 of these 5 groups the bubble seems to "burst" because price forecasts are restricted to be below 1000. In group 6 , however, the bubble bursts earlier (the maximum value of the asset price in that group is 749.62 in period 29), which can therefore not be attributed to the existence of the upper limit. ${ }^{7}$ Notice also that the upper bound of 1000 is approximately 16 times the fundamental price $p^{f}=60$. In group 1 the upper bound is not reached, but the maximum realized asset price is still a factor 3 or 4 larger than the fundamental price.

Let us now describe some other general features of the evolution of asset prices. First consider the 'atypical' group 1, where no bubble occurs. In this group there are some sudden jumps in the asset price. These jumps are due to very high predictions of individual participants. ${ }^{8}$ Apart from these jumps, the time series of the realized prices

\footnotetext{
${ }^{5}$ Alternatively, one could reward participants according to realized utility $U_{h, t+1}$, which is maximized at $p_{h, t+1}^{e}=p_{t+1}$. The experimental data show that for the individuals within an experimental group the correlation between average realized utility and average squared prediction error is perfect. Moreover, the difference between realized utility and the highest at tainable utility level (obtained for $p_{h, t+1}^{e}=p_{t+1}$ ) is proportional to the quadratic forecast error (see Hommes 2001). Using quadratic forecast error as a performance measure therefore seems to be equivalent with using realized utility. Another interesting option is to reward participants according to realized profits or according to a weighted average of quadratic forecast error and realized profits. We leave this for future work.

${ }^{6} \mathrm{~A}$ complete set of data will be made available upon request.

${ }^{7}$ In each of the groups 2 to 5 there are at least 4 participants with a highest prediction of 999 or 1000, whereas the highest prediction in group 6 is 906 .

${ }^{8}$ For period 7 participant 6 predicts a price of 448.70 , for period 11 participant 1 predicts a price of 1000 and for period 29 participant 6 predicts a price of 908.80. A similar sudden jump occurs in period 14 in group 5, where participant 3 predicts a price of 1000 for period 15 .
} 

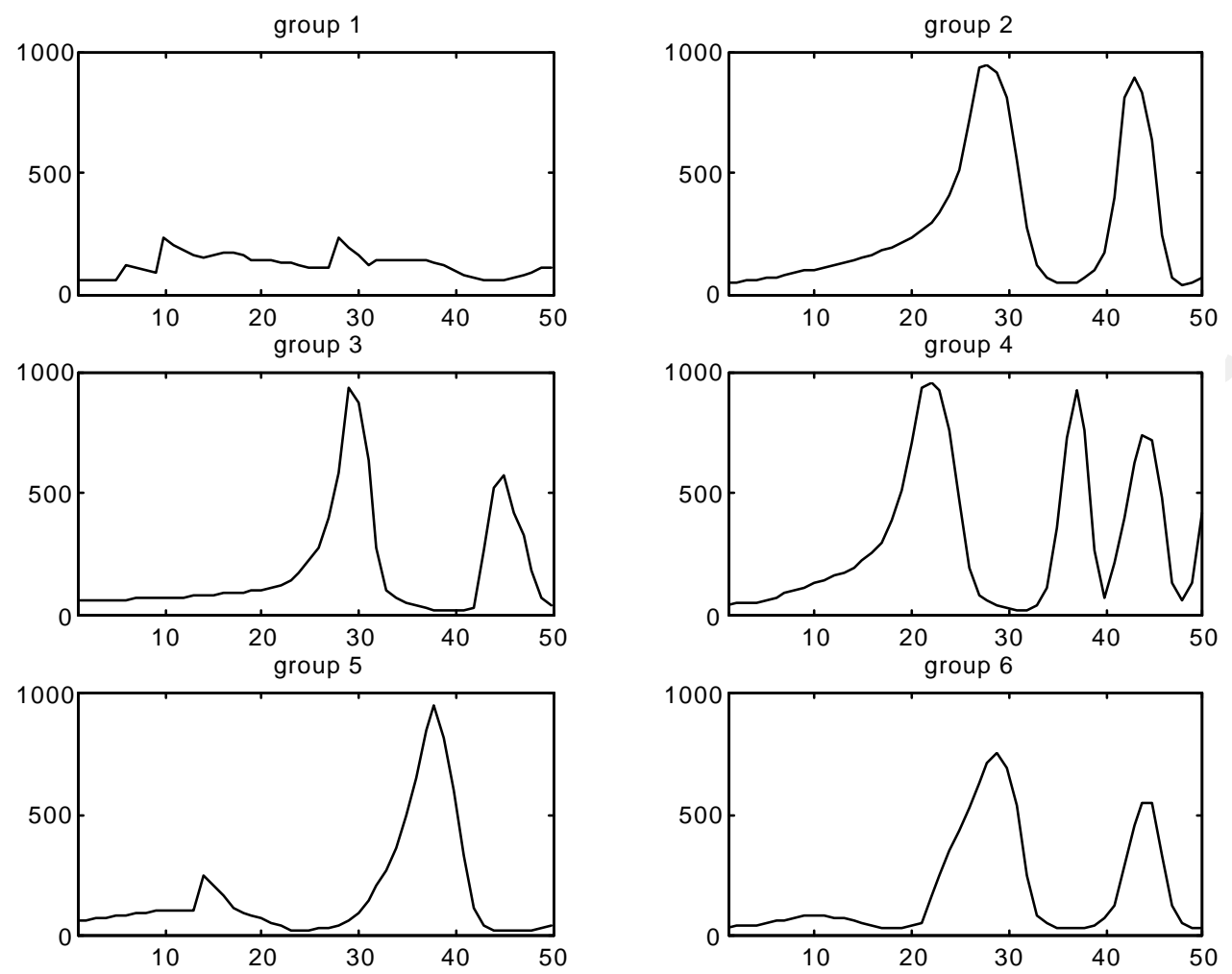

Figure 3: Realized prices in the experiment for the different groups.

moves towards the fundamental price of 60 in an oscillatory fashion. Also for groups 5 and 6 prices seem to settle down in the first 20 periods, after which the emergence of the bubble is "triggered". Now let us turn to groups 2 to 6 and consider what happens when prices approach 1000. Since there is an upper bound on predictions, the realized price will eventually stop increasing. ${ }^{9}$ Predictions will decrease, which will be followed by a decrease in realized prices. For all groups (except group 6) the price subsequently falls to the lowest value since the start of the experiment. ${ }^{10}$ After this minimum the price increases again and reaches another peak (except for group 5 ), which is typically rather high but not as high as the first peak. Subsequently the price decreases again (followed by yet another peak in group 4). This suggest that the dynamics in most of the groups is driven by the interaction between participants trying to extrapolate trends and the restrictions on the price predictions of 0 and 1000. Also, since the height of the respective "booms" decreases over time and the frequency with which these booms occur increases, one might conjecture that the realized prices

${ }^{9}$ Actually, the maximum value the realized price can attain is $p_{\max }=\frac{20}{21}(1000+3)=955 \frac{5}{21}$. In groups 2, 3, 4 and 5 the price actually comes close to this maximum price $(934.54,931.11,954.75$, 940.16, with implied averages predictions of 978.27,974.67, 999.49 and 984.17, respectively) and in group 6 the highest realized price is 749.62 (with an implied average prediction of 784.1), which is also more than 12 times the fundamental price.

${ }^{10}$ The subsequent minimum prices for groups $2-6$ are given by $36.95,9.68,9.21,12.56$ and 27.29 , respectively. 

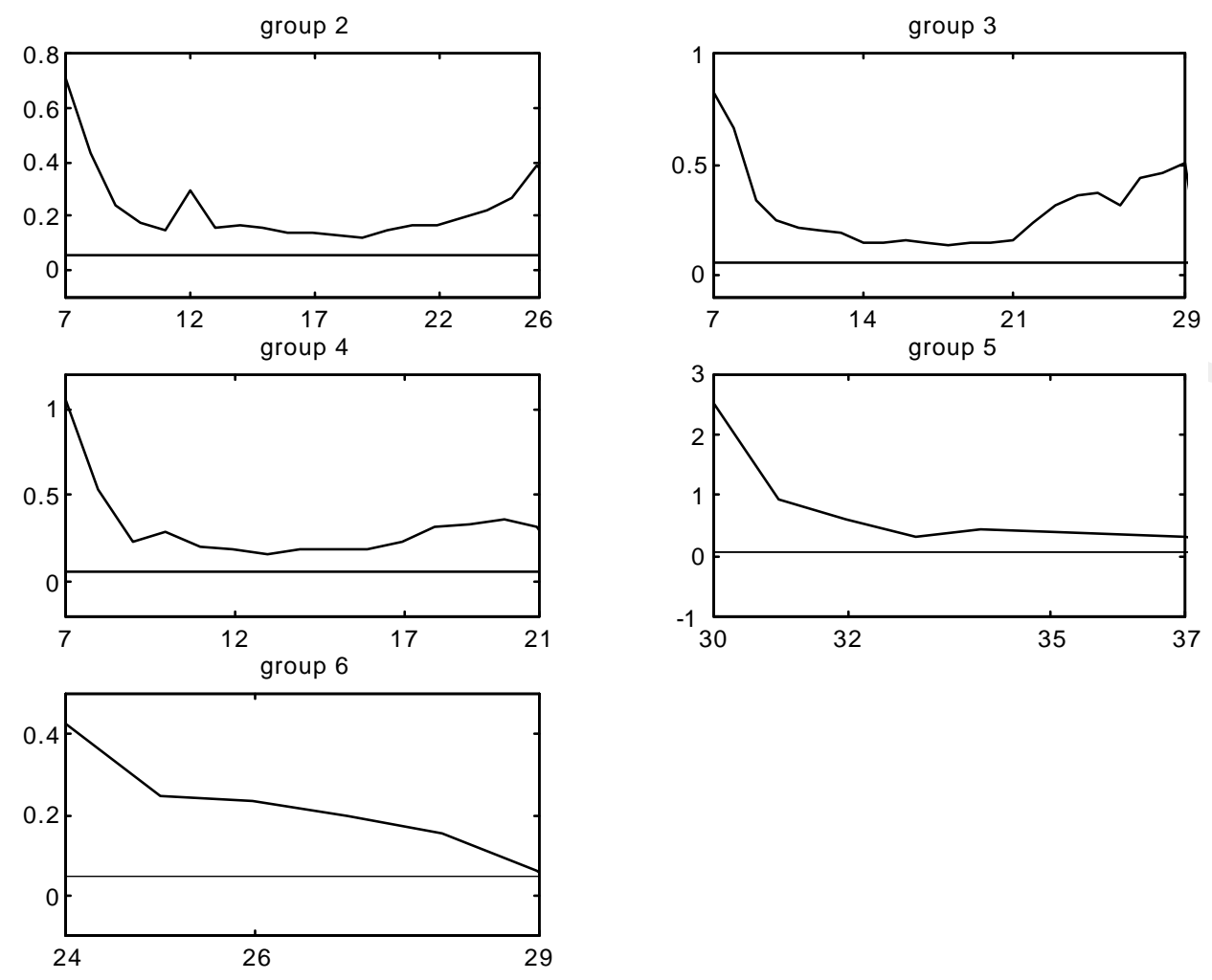

Figure 4: Plots of $q_{t+1}-q_{t}$ against $t$ for groups $2-6$. The horizontal lines reflect the corresponding value along a rational bubble (i.e. $\ln R \approx 0.0488$ ).

will eventually converge to the neighborhood of the fundamental price.

We analyze the behavior of the asset prices along the first bubble further by considering the following two questions: $i$ ) do the observed bubbles correspond to rational bubbles? ii) is the experimental asset market efficient?

\subsection{The nature of the experimental bubbles}

Along a rational bubble we have $p_{t}=p^{f}+R^{t} c$ (i.e., prices grow with a constant rate, the risk free gross rate of return $R=1+r)$. Now consider the series $q_{t}=\ln \left(p_{t}-p^{f}\right)$. If prices evolve according to a rational bubble we have $q_{t}=\ln c+t \ln R$ and $q_{t+1}-q_{t}=$ $\ln R$. Figure 4 plots $q_{t+1}-q_{t}$ against $t$ for groups $2-6$.

A few remarks on the data we use are in order. Since the upper bound on price predictions flattens the last part of the bubble, the last observation we take into account is the last one that satisfies $p_{t}-p_{t-1}>p_{t-1}-p_{t-2}$. On the other hand, $q_{t}$ only exists when the price is above the fundamental value, and since in all experiments the price starts out below the fundamental value, we discard the first few observations. We also want to allow for some coordination and learning. Therefore we use observations starting at period $t=7$, except for groups 5 and 6 where a bubble sets in after quite some time. The number of observations along the bubble for the last two groups is 
pretty small. From Figure 4 it follows that, although over some intervals $q_{t+1}-q_{t}$ seems to be approximately constant, its value is much higher than $\ln R \approx 0.0488$. From this we conclude that the bubbles observed in the experiment do not correspond to rational bubbles, but seem to be speculative bubbles driven by the (boundedly rational) prediction strategies of the participants. ${ }^{11}$ Table 1 shows, for each group, the average value of $q_{t+1}-q_{t}$ along the bubble, the implied growth rate $\widehat{R}$ and the theoretical growth rate $R$ of a rational bubble. In all groups, except for group 5, the mean value of $q_{t+1}-q_{t}$ is significantly different from $\ln R \approx 0.0488$ at the $5 \%$ significance level.

\begin{tabular}{|c||c|c|c|c|}
\hline group & $\overline{q_{t+1}-q_{t}}$ & $\widehat{R}$ & $R$ & sample \\
\hline \hline 2 & 0.222 & $1.248^{*}$ & 1.050 & $7-26$ \\
3 & 0.292 & $1.339^{*}$ & 1.050 & $7-29$ \\
4 & 0.310 & $1.363^{*}$ & 1.050 & $7-21$ \\
5 & 0.227 & 1.255 & 1.050 & $29-37$ \\
6 & 0.271 & $1.311^{*}$ & 1.050 & $23-29$ \\
\hline
\end{tabular}

Table 1: Test of the rational bubbles hypothesis. A * indicates that the estimate of $\widehat{R}$ is significantly different from 1.050 at the $5 \%$ level.

Let us conclude this discussion about the bubbles with two observations. First, since there is no exogenous uncertainty in the model rational agents would make no forecast errors along the bubble and hence have high earnings. Since the average earnings (see Appendix $C$ ) are fairly low this is not the case in the experiment. Secondly, given that the first price is below 100 and for a rational bubble the growth rate equals $R$, along a rational bubble the price approaches 1000 not sooner than at $t=65$ (since $60+40 \times 1.05^{64}=968$ ).

From this analysis we conclude that our laboratory asset pricing experiments exhibit endogenous speculative bubbles. An explanation for this is that participants try to extrapolate trends. If, by accident, prices increase slightly and agents perceive this increase, they tend to extrapolate the trend and expect a further price increase. Due to the selfconfirming nature of the asset pricing model, this leads to an actual price increase, which is extrapolated again. Clearly, this process will lead to a price bubble. This mechanism is also consistent with the results in groups 5 and 6 . There it seems that the asset price is relatively stable for quite some time until it starts to increase somewhat. This increase in the price is perceived by the participants as an upward trend, which they subsequently extrapolate, leading to the explosion of prices. Following the literature on positive feedback trading (see for example De Long et al.) we refer to this trend chasing behavior as positive feedback expectations. Unfortunately, this type of behavior fails to explain why the bubbles in groups 5 and 6 do not occur earlier and why the bubble in group 6 bursts prematurely.

\footnotetext{
${ }^{11}$ The use of the word "speculative" does not mean that participants can enter into speculative trades by buying and selling the asset, but refers to the speculative or extrapolative expectations participants use.
} 

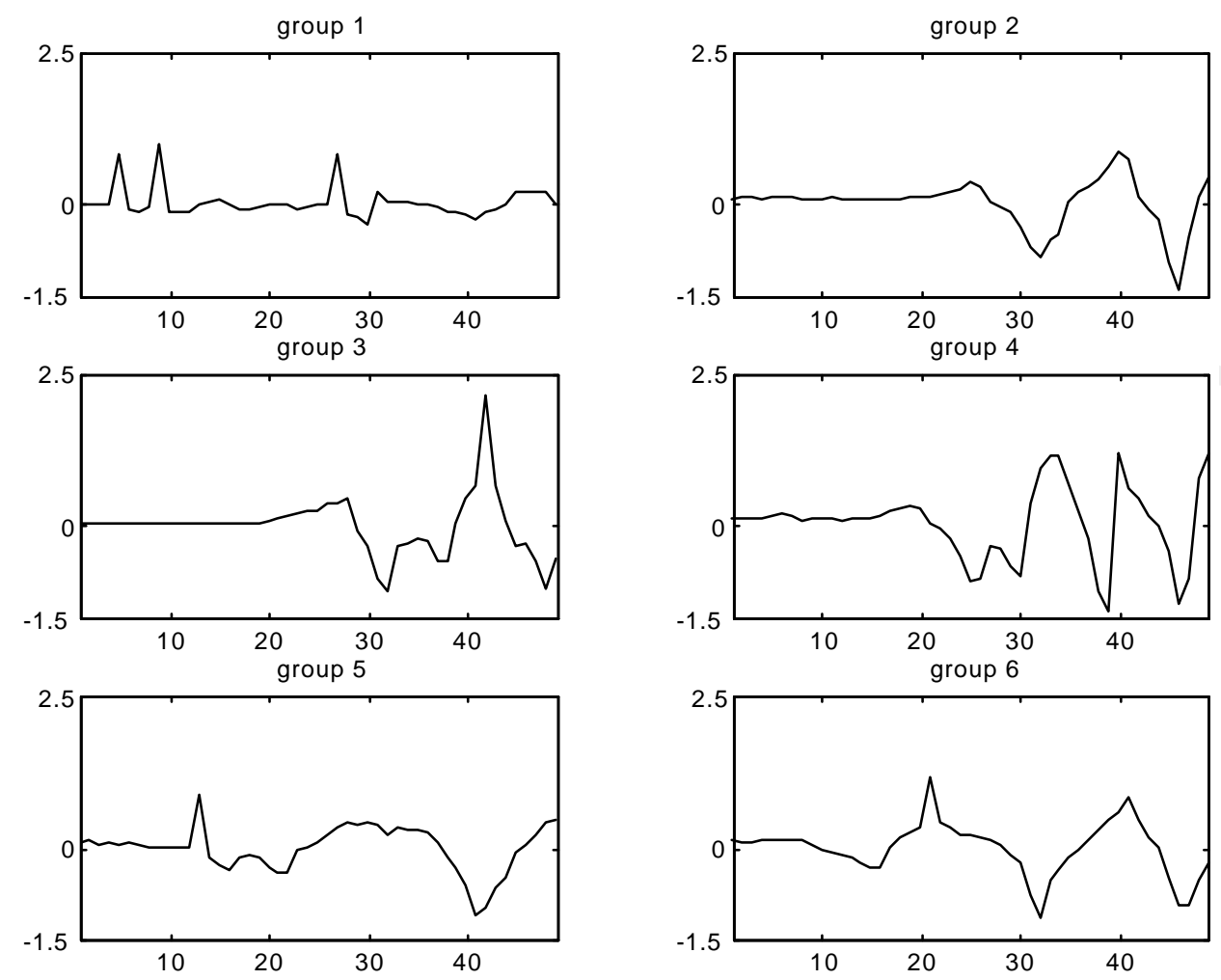

Figure 5: Excess returns of realized asset prices.

\subsection{Efficiency and predictability}

A celebrated result from the theory on financial markets is the so-called efficient market hypothesis. This hypothesis claims that all information on an asset is incorporated in its price, and it implies that one cannot obtain above "normal" profits by trading on a financial market. An implication of this hypothesis is that the excess returns $x_{t}=\ln p_{t}-\ln p_{t-1}$ are uncorrelated with past information. In particular, the excess returns should not show serial correlation; otherwise traders can improve their prediction of the excess return by using its past values. Although the financial markets in our experiment are highly stylized, we believe that we might learn more about aggregate market behavior by investigating excess returns. Figure 5 shows the excess returns in the six different groups.

For groups 2 to 6 , there appears to be serial correlation in the excess returns over the full sample of 50 periods. However, this serial correlation in returns is mainly due to the large amplitude fluctuations in the last part of the return series after the price series reaches its upper bound. Since the upper bound of 1000 is in fact an artifact of our experimental setup to stop an exploding asset price, it is more interesting to investigate informational (in)efficiency before the bubble reaches its upper bound. Figure 6 shows the first 10 lags of the autocorrelation function where only observations along the first bubble (i.e., the first 26, 29, 21, 37 and 29 observations in groups 2, 3, 4,5 and 6 , respectively) are used. Notice that when forecasting the price or return at 

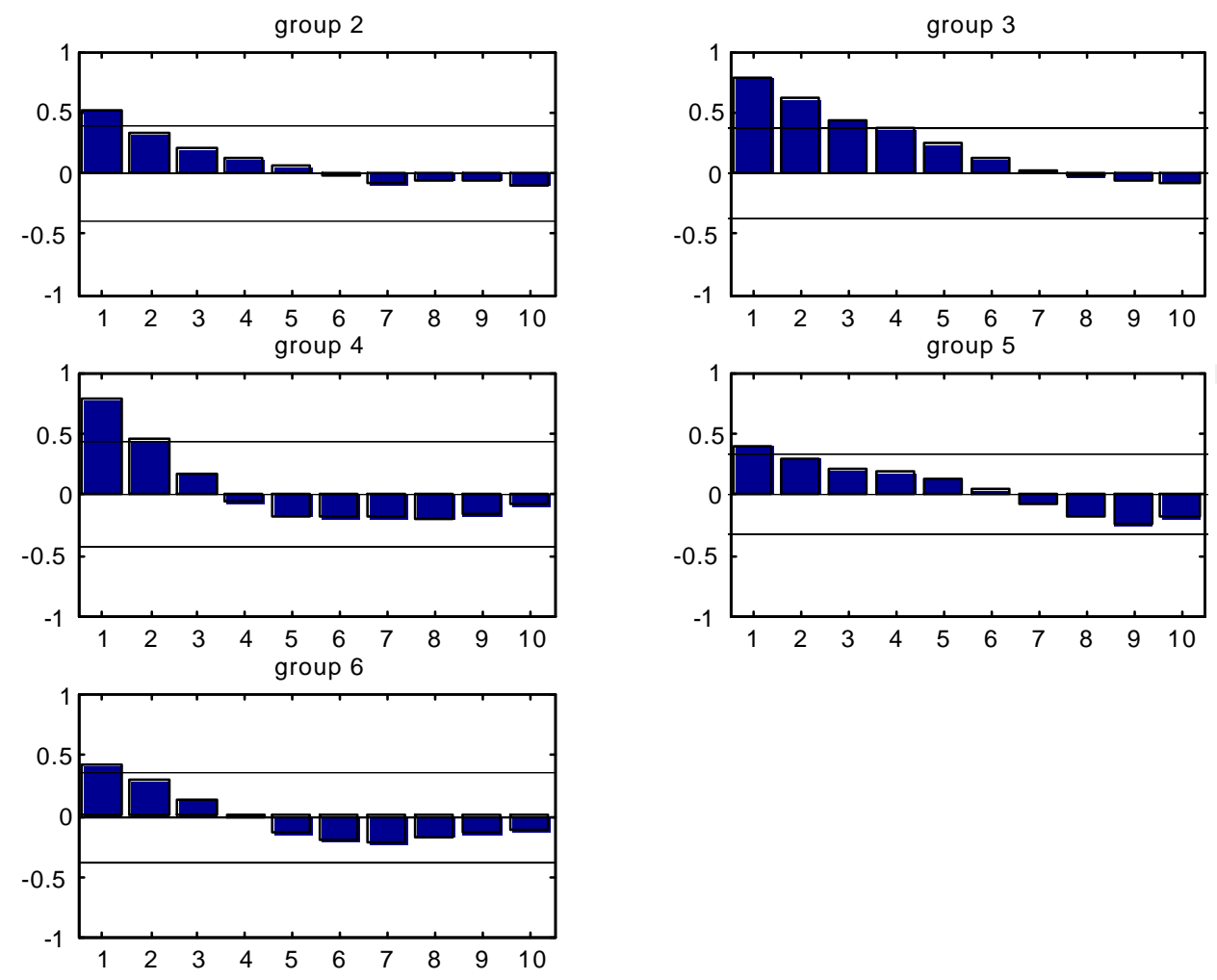

Figure 6: Autocorrelation functions of the excess returns along the first bubble. We consider the first 26, 29, 21, 37 and 29 observations. The horizontal lines in the autocorrelation plots are the two standard error bounds at the $5 \%$ significance level.

date $t$, only past prices or returns up to date $t-2$ are in the information set so that a significant first order autocorrelation coefficient can not be exploited. During the first part of the bubble the market seems to be approximately efficient according to our autocorrelation test. Only group 3 is not fully informationally efficient, since it has a significant second order autocorrelation coefficient. Market efficiency is sometimes also defined in terms of whether prices reflect economic fundamentals. Since in 5 out of the 6 groups prices show large deviations from the rational expectations fundamental price, our asset pricing experiments are not efficient in this sense.

\section{$5 \quad$ Individual prediction strategies}

We now turn to the individual prediction strategies of the participants in our asset pricing experiment. Figure 7 shows, per group, the individual predictions of all participants. Typically, the differences between prediction strategies within groups are small. This suggests that the different participants in a group coordinate on some common prediction strategy, at least qualitatively.

This coordination of expectations is obtained in all six groups. To quantify our qualitative observation that participants within a group coordinate on a common pre- 

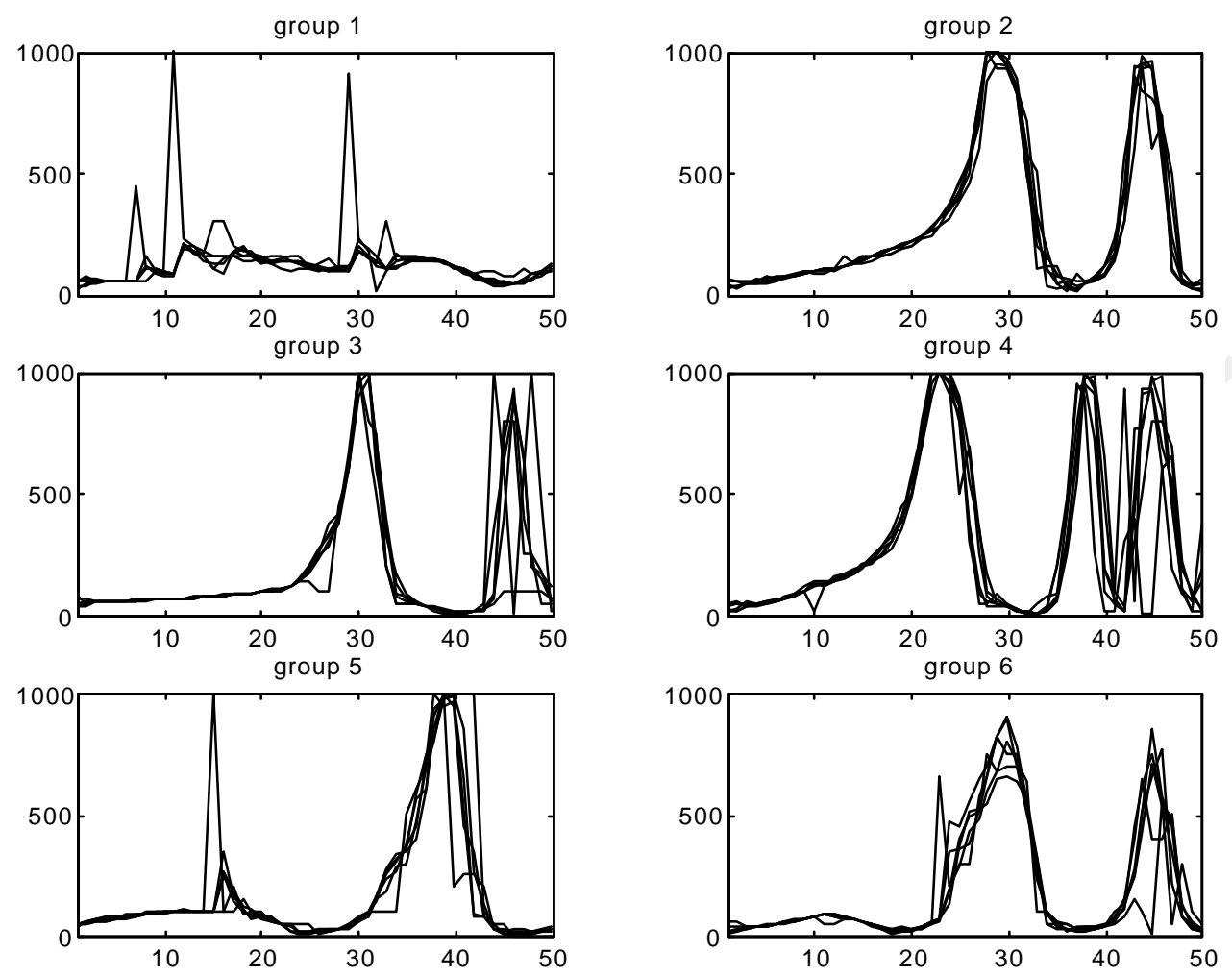

Figure 7: Participants' individual predictions per group.

diction strategy we consider, for each group, the average individual quadratic forecast error $\frac{1}{T_{0} H} \sum_{h=1}^{H} \sum_{t=t_{0}+1}^{T}\left(p_{h t}^{e}-p_{t}\right)^{2}$, which corresponds to the individual quadratic forecast error averaged over time and over participants within a group. This average is based upon the last $T_{0} \equiv T-t_{0}$ observations in order to abstract from variations in predictions and prices in the beginning of the experiment that are due to participants trying to learn how to predict prices accurately. It is easily verified that this average individual quadratic forecast error can be broken up in two separate terms, as follows

$$
\frac{1}{T_{0} H} \sum_{h=1}^{H} \sum_{t=t_{0}+1}^{T}\left(p_{h t}^{e}-p_{t}\right)^{2}=\frac{1}{T_{0} H} \sum_{h=1}^{H} \sum_{t=t_{0}+1}^{T}\left(p_{h t}^{e}-\bar{p}_{t}^{e}\right)^{2}+\frac{1}{T_{0}} \sum_{t=t_{0}+1}^{T}\left(\bar{p}_{t}^{e}-p_{t}\right)^{2}
$$

where $\bar{p}_{t}^{e}=\frac{1}{H} \sum_{h=1}^{H} p_{h t}^{e}$ is the average prediction for period $t$ in a group (averaged over individuals in that group). The first term on the right-hand side of (9) measures the dispersion between individual predictions, and we will refer to it as average dispersion error. It gives the squared distance between the individual prediction and the average prediction $\bar{p}_{t}^{e}$ within the group, averaged over time and participants. Note that it equals 0 if and only if all participants in one group use exactly the same prediction strategy. Hence, a small average dispersion implies coordination on a common prediction strategy. The second term on the right-hand side of (9) measures the average squared distance between the mean prediction $\bar{p}_{t}^{e}$ and the realized price $p_{t}$. 
We will refer to this second term as the average common error. If individual expectations can be described as "rational expectations with error", where the error has mean zero and is serially uncorrelated and uncorrelated with the errors of the other participants, then we should expect that individual forecast errors cancel each other out in the aggregate. ${ }^{12}$ If this is the case then this second term should be relatively small.

Table 2 shows, for each of the six groups, how the average quadratic forecast error is broken up in these two terms. Here $t_{0}$ is taken to be equal to 10 .

\begin{tabular}{|c|c|c|c|}
\hline & avg. individual error & avg. dispersion error & avg. common error \\
\hline group & $\frac{1}{T_{0} H} \sum_{h . t}\left(p_{h t}^{e}-p_{t}\right)^{2}$ & $\frac{1}{T_{0} H} \sum_{h . t}\left(p_{h t}^{e}-\bar{p}_{t}^{e}\right)^{2}$ & $\frac{1}{T_{0}} \sum_{t}\left(\bar{p}_{t}^{e}-p_{t}\right)^{2}$ \\
\hline \hline 1 & 6.5 & $5.8(89 \%)$ & $0.7(11 \%)$ \\
\hline 2 & 22.8 & $2.6(11 \%)$ & $20.2(89 \%)$ \\
\hline 3 & 28.8 & $13.0(45 \%)$ & $15.8(55 \%)$ \\
\hline 4 & 50.1 & $16.6(33 \%)$ & $33.6(67 \%)$ \\
\hline 5 & 18.7 & $10.0(53 \%)$ & $8.7(47 \%)$ \\
\hline 6 & 16.5 & $6.8(41 \%)$ & $9.7(59 \%)$ \\
\hline
\end{tabular}

Table 2: Different measures for the individual prediction strategies (in thousands). Between brackets is the percentage of the average individual error that can be attributed to the average dispersion error and the average common error, respectively.

From Table 2 it is clear that at least for groups $2-6$, only a relatively small part (ranging from $11 \%$ in group 2 to $53 \%$ in group 5 ) of the average quadratic forecasting error (first column) can be explained by the dispersion in expectations (second column). ${ }^{13}$ This confirms our conjecture that there is coordination on a common prediction strategy. The observation that a relatively large part of the average quadratic forecast error is due to the difference between the average expectation and the realized price (third column) implies that "rational expectations with error" is not a good description of participants' expectation formation. In fact, it suggests that participants' mistakes are correlated. We therefore conclude that participants make significant forecasting errors, and they are alike in the way that they make these forecasting errors.

\footnotetext{
${ }^{12}$ This is consistent with Muth (1961, p.316) who gives the following formulation of the rational expectations hypothesis: "The hypothesis can be rephrased a little more precisely as follows: that expectations of firms (or, more generally, the subjective probability distribution of outcomes) tend to be distributed, for the same information set, about the prediction of the theory (or the "objective" probability distributions of outcomes)." In other words, individual expectations may be wrong, but in the aggregate expectations should be approximately correct.

${ }^{13}$ Recall that in group 1 in periods 7, 11 and 29 , the realized price is disturbed by an extreme prediction by one of the participants. The relatively high dispersion of expectations in group 1 can be attributed to these periods. If we exclude these three periods we find averages (in thousands) of 1.3, 0.6 and 0.7 respectively. These latter numbers are consistent with the results for the other groups.
} 
The analysis of Table 2 suggests that participants make structural forecast errors. Note that if participants' forecast error is correlated with available information, they can improve their prediction. To test whether participants exploit the available information optimally we computed, for each participant, the first 10 lags of the autocorrelation function of the time series of forecast errors $p_{t}-p_{h t}^{e}$, where we again only used the last 40 observations. The significant lags are presented in Table 3.

\begin{tabular}{|c||c|c|c|c|c|c|}
\hline & group 1 & group 2 & group 3 & group 4 & group 5 & group 6 \\
\hline \hline part. 1 & - & $1-4-5$ & - & $1-3-4-10$ & 1 & - \\
\hline part. 2 & - & $1-5-6$ & 1 & $1-3-4-10$ & 1 & $1-9-10$ \\
\hline part. 3 & - & $1-4$ & 1 & 1 & 1 & $1-2$ \\
\hline part. 4 & 1 & $1-4-5$ & - & $1-3-4$ & - & $1-2-9$ \\
\hline part. 5 & - & $1-4$ & $1-2$ & $1-3-4-10$ & 1 & $1-9-10$ \\
\hline part. 6 & - & $1-2-5-9$ & 1 & 4 & 1 & $1-9-10$ \\
\hline
\end{tabular}

Table 3: Autocorrelation structure of individual forecast errors

Notice that the autocorrelation function of the forecast errors is significant at the first lag for many participants. However, participants do not have $p_{t}$ in their information set when predicting $p_{t+1}$. Hence, they are not able to exploit the first order autocorrelation structure in the forecast errors to improve their predictions. Therefore we should focus on higher order lags of the autocorrelation function. We thus find that for about half of the participants there is no exploitable structure in the forecast errors. Notice that the differences between autocorrelation patterns of participants within groups is much smaller than the differences of the autocorrelation patterns between groups. Participants in group 1 have almost no structure in their forecast errors, whereas most participants in groups 3 and 5 only have significant autocorrelation at the first lag, which is innocuous. There is much more structure in the forecast errors of the participants from groups 2, 4 and 6. The fact that autocorrelation of individual forecasting errors in groups 2, 4 and 6 are similar suggests that individual forecasting error in these groups are correlated. Half of the participants do not exploit all structure in the forecast errors. For these participants it might be the case that they are still in the process of exploiting this structure by adapting their prediction strategies. The analysis of the individual prediction strategies leads us to the conclusion that participants make structural forecasting errors and deviate from rationality, but they tend to deviate from rationality in a common way. Finally, it is interesting to consider only the observations along the first bubbles (the first 23, 26, 18, 27 and 28 observations for groups 2, 3, 4, 5 and 6). Along these first bubbles we find significant lags of the autocorrelation function of the forecast errors for only 8 participants. That is, a vast majority of the participants do not make structural forecast errors until the price has reached its upper bound. 


\section{Concluding Remarks}

In this paper we investigated expectation formation in a stationary asset pricing experiment. Participants have sufficient information to compute the constant rational expectations fundamental price. In 5 of the 6 experiments a price bubble emerges endogenously with prices attaining values of 16 times their fundamental value. The growth rates of these experimental bubbles are inconsistent with rational expectations.

The bubbles observed in our experiment seem to be triggered by the trend following behavior of participants: when observing a small price increase, they predict the price to increase even further, after which this price increase becomes self-fulfilling. These positive feedback expectations seem to drive much of the dynamics. Although the experimental bubbles do not correspond to rational bubbles the excess returns of the asset along the first bubble does not exhibit a significant autocorrelation structure. In this sense the market is informationally efficient. At an individual level, the analysis in Section 5 has revealed that the average dispersion between individual prediction strategies of participants within a group tends to be relatively small in comparison to their average individual forecast error. This suggests that individuals seem to coordinate on a common prediction strategy.

It is worthwhile confronting our experimental results with some theoretical work on expectation formation and learning. In a recent paper, Guesnerie discusses the concept of strong rationality as a way to evaluate theoretical possibilities of coordination of economic predictions on a particular equilibrium. A rational expectations steady state solution is strongly rational if common knowledge of the agents that the equilibrium is in some neighborhood of the rational expectations steady state implies that the equilibrium must be equal to the steady state; see Guesnerie for a detailed discussion. Guesnerie argues that an equilibrium that is not strongly rational cannot be self-enforcing. It follows directly from his results that the rational expectations fundamental price in the asset pricing model considered here is (globally) strongly rational, and therefore in theory the fundamental steady state may be self-enforcing. However, in our asset pricing model experiments participants are unable to learn the fundamental price; instead, in 5 out of 6 groups, participants learn to coordinate on an exploding bubble solution.

Evans and Honkapohja provide an extensive recent survey of theoretical work on expectation formation and learning. They emphasize the concept of expectational stability (E-stability) of rational expectations solutions. A rational expectations solution is E-stable if a recursive stochastic learning algorithm, such as ordinary least squares (OLS), converges to this solution. In the representative agent asset pricing model under learning, the fundamental price is E-stable, whereas the rational bubbles are not E-stable; see Evans and Honkapohja (Section 9.7, pp.220-222). This theory thus predicts that boundedly rational agents observing time series of past prices are able to learn the rational expectations fundamental price. In contrast with these theoretical results, in our asset pricing experiments heterogeneous participants are unable to learn the fundamental price, but instead learn to coordinate on an exploding bubble solution. It is remarkable that Evans and Honkapohja (p.222) point out 
that "for some initial values of parameter estimates, the paths under learning will not converge to the fundamental solution but instead follow a nonrational divergent trajectory". The bubbles observed in our experimental results seem to be consistent with this possibility of a 'nonrational divergent trajectory'.

Clearly, there are significant discrepancies between the predictions of theoretical models such as least squares learning, strong rationality and expectational stability and the outcomes of the experiment. However, some care should be taken in interpreting those discrepancies since the information requirements for the theoretical models are not satisfied in the experiment. In the experiment, for example, it was not common knowledge that the price was below 1000, let alone that the price was in a small neighborhood around the fundamental price, as is required for strong rationality. Also notions of E-stability and (real-time) adaptive learning assume that people know at least the correct structure of the underlying asset pricing economy.

The recurring bubbles and crashes observed in our experiments are similar to the periodically collapsing bubbles studied by Blanchard (1979), Blanchard and Watson (1982) and Evans (1991). These (rational) bubbles collapse with a certain probability each period and restart again after a collapse. As long as they do not collapse they have to grow faster than a 'regular' rational bubble, as was also the case in our experiments. The observed crashes in our experiments however seem to be mainly caused by new information about the upper bound of 1000, entering the market as soon as one of the participants finds out about the upperbound when trying to enter a forecast larger than 1000. Only in group 6 does the bubble stop and reverse without prices and forecasts reaching their maximum upper bound. These bubbles and crashes are consistent with the type of evolutionary learning introduced in Brock and Hommes (1997). In particular, Brock and Hommes (1998) apply this evolutionary framework to the same asset pricing model with heterogeneous beliefs that underlies our experiments. Evolutionary switching of boundedly rational agents between trend following strategies and fundamental market analysis indeed produces recurring bubbles and crashes similar to our experimental results.

Finally, we relate our finding that participants coordinate on a common prediction strategy to some related recent experimental work on expectation formation. First note that this coordination result is particularly striking since participants do not observe each others' predictions and therefore can only coordinate through the realized market prices. Moreover, along these common prediction strategies significant forecast errors are made. Hommes et al. investigate expectation formation in a closely related asset pricing model extended with a robot trader, believing that prices will move in the direction of the fundamental. In the presence of the robot trader speculative bubbles occur less frequently and are not as strong. In these experiments coordination on a common prediction strategy was also found, suggesting that this coordination is a robust feature in this type of experiment. Van de Velden investigates expectation formation in an experimental cobweb model of a commodity market with a production lag. It turns out that in this cobweb experiment participants are able to learn the correct price level (although there is excess volatility in prices for treatments where the cobweb model is unstable under naive expectations). No coordination of prediction seems to take place in this experiment. To understand this it 
is important to note that the cobweb model has an expectations reversing structure: a high predicted price leads to a high production level and therefore to a low realized market equilibrium price and vice versa. There is therefore an incentive to disagree with the majority of the other participants. This helps participants learn the correct price level. In contrast, the asset pricing model discussed in the present paper has an expectations confirming structure in the sense that a high predicted price leads to a high demand for the risky asset and therefore to a high market equilibrium price. In the asset pricing framework participants do not seem to be able to learn the fundamental price level. The market institution and the nature of the expectations feedback structure therefore seem to play a pivotal role in the dynamics of market equilibrium prices. Heemeijer et al. (2006) test this hypothesis by running an experiment on expectation formation with two treatments that are equivalent in all dimensions except for the sign of the expectations feedback structure. In the positive feedback treatment with an expectations confirming structure, there are persistent deviations from fundamentals and coordination on a common prediction strategy, and in the negative feedback structure, with an expectations reversing structure, there is fast convergence to the fundamental value and no coordination of predictions before the steady state is reached. More experimental work on expectation formation and learning in dynamic markets is useful to understand which expectations hypothesis is most relevant in economic modelling.

\section{References}

Andreassen, P.B., Kraus, S.J., 1990. Judgemental extrapolation and the salience of change. Journal of Forecasting 9, 347-372.

Barberis, N., Thaler, R., 2003. A survey of behavioral finance. In: Constantinides, G.M., Harris, M., Stulz, R.M. (Eds.). Handbook of the Economics of Finance. Amsterdam: North-Holland, 1053-1123.

Blanchard, O., 1979. Speculative bubbles, crashes and rational expectations. Economic Letters 3, 387-389.

Blanchard, O., Watson, M., 1982. Bubbles, rational expectations, and financial markets. In: Wachtel, P. (Ed.). Crises in the Economic and Financial Structure. Lexington: Lexington Books, 295-316.

Brock, W.A., Hommes, C.H., 1997. A rational route to randomness. Econometrica 65, 1059-1095.

Brock, W.A., Hommes, C.H., 1998. Heterogeneous beliefs and routes to chaos in a simple asset pricing model. Journal of Economic Dynamics and Control 22, 12351274 .

De Bondt, W.F.M., 1993. Betting on trends: intuitive forecasts of financial risk and return. International Journal of Forecasting 9, 355-371. 
De Long, J.B., Shleifer, A., Summers. L.H., Waldmann, R.J., 1990. Positive feedback investment strategies and destabilizing rational speculation. Journal of Finance 45, 379-396.

Diba, B.T., Grossman, H.I., 1988. The theory of rational bubbles in stock prices. Economic Journal 98, 746-754.

Dwyer, G.P., Williams, A.W., Battalio, R.C., Mason, T.I., 1993. Tests of rational expectations in a stark setting. Economic Journal 103, 586-601.

Evans, G.W., 1991. Pitfalls in testing for explosive bubbles in asset prices. American Economic Review 81, 922-930.

Evans, G.W., Honkapohja, S., 2001. Learning and Expectations in Macroeconomics. Princeton: Princeton University Press.

Flood, R.P., Garber, P.M., 1980. Market fundamentals versus price bubbles: the first tests. Journal of Political Economy 88, 745-770.

Frankel, J.A., Froot. K.A., 1987. Using survey data to test standard propositions regarding exchange rate expectations. American Economic Review 77, 133-153.

Frankel, J.A., Froot, K.A., 1988. Chartists, fundamentalists and the demand for dollars. Greek Economic Review 10, 49-102.

Froot, K.A., Obstfeld, M., 1991. Intrinsic bubbles: the case of stock prices. American Economic Review 81, 1189-1214.

Garber, P.M., 1990. Famous first bubbles. Journal of Economic Perspectives 4(2), $35-54$.

Guesnerie, R., 2002. Anchoring economic predictions in common knowledge. Econometrica 70, 439-480.

Heemeijer, P., Hommes, C.H., Sonnemans, J., Tuinstra, J., 2006. Price stability and volatility in markets with positive and negative expectations feedback. An experimental investigation. CeNDEF Working Paper 06-05, Universiteit van Amsterdam.

Hey, J.D., 1994. Expectation formation: rational or adaptive or ...? Journal of Economic Behavior and Organization 25, 329-349.

Hirshleifer, D., 2001. Investor psychology and asset pricing. Journal of Finance 56, 1533-97.

Hommes. C.H., 2001. Financial markets as complex adaptive evolutionary systems. Quantitative Finance 1, 149-167.

Hommes, C.H., Sonnemans, J. Tuinstra, J., van de Velden, H., 2005. Coordination of expectations in asset pricing experiments. Review of Financial Studies 18, 955-980. 
King, R.R., Smith, V.L., Williams, A.W., van Boening, M., 1993. The robustness of bubbles and crashes in experimental stock markets. In: Prigogine, I., Day, R., Chen, P. (Eds.). Nonlinear Dynamics and Evolutionary Economics. Oxford: Oxford University Press, 183-200.

Lei, V., Noussair, C.N., Plott, C.R., 2001. Nonspeculative bubbles in experimental asset markets: lack of common knowledge of rationality vs. actual irrationality. Econometrica 69, 831-859.

Marimon, R., Spear, S.E., Sunder, S., 1993. Expectationally driven market volatility: an experimental study. Journal of Economic Theory 81, 74-103.

Muth, J.F., 1961. Rational expectations and the theory of price movements. Econometrica 29, 315-335.

Noussair, C.N., Robin, S., Ruffieux, B., 2001. Price bubbles in laboratory asset markets with constant fundamental values. Experimental Economics 4, 87-105.

Porter, D.P., Smith, V.L., 1995. Futures contracting and dividend uncertainty in experimental asset markets. Journal of Business 68, 509-541.

Santos, M.S., Woodford, M., 1997. Rational asset pricing bubbles. Econometrica 65, $19-57$.

Schmalensee, R., 1976. An experimental study of expectation formation. Econometrica $44,17-41$.

Shiller, R.J., 1990. Speculative prices and popular models. Journal of Economic Perspectives 4(2), 55-65.

Smith, V.L., Suchanek, G.L., Williams, A.W., 1988. Bubbles, crashes and endogenous expectations in experimental spot asset markets. Econometrica 56, 1119-1151.

Smith, V.L., van Boening, M., Wellford, C.P., 2000. Dividend timing and behavior in laboratory asset markets. Economic Theory 16, 567-583.

Tirole, J., 1982. On the possibility of speculation under rational expectations. Econometrica 50, 1163-1181.

Tirole, J., 1985. Asset bubbles and overlapping generations. Econometrica 53, 14991528.

van de Velden, H., 2001. An Experimental Approach to Expectation Formation in Dynamic Economic Systems. Dissertation, Universiteit van Amsterdam.

West, K.D., 1987. A specification test for speculative bubbles. Quarterly Journal of Economics 102, 553-580.

Williams, A.W., 1987. The formation of price forecasts in experimental markets. Journal of Money, Credit and Banking 19, 1-18. 